\title{
Research on the Cultivation of College Students' Legal Awareness
}

\author{
Zhang Xiaoduo \\ Weinan Normal University, Weinan, Shanxi, China, 714099
}

Keywords: College Students, Status Quo of Legal Awareness, Reason Analysis, Ways of Training

\begin{abstract}
Undergraduate is the hope of social progress and development. The improvement of law consciousness of undergraduates is not only of great significance for building a society ruled by law, but also the key to improving legal literacy of all citizens. By analyzing the present situation and existing problems of law consciousness of undergraduates, the paper tries to sum up the main ways in raising college students’ legal awareness.
\end{abstract}

\section{Introduction}

Legal consciousness is a form of social consciousness, and it refers to people's views on the law and related legal phenomena and feelings, attitudes, general term. It shows the various theories to explore the legal phenomenon, the evaluation and interpretation of the current law, people's law motivation, understanding of one's own rights and obligations, understanding of the law and legal system, the degree of mastery and application, and the evaluation of the validity of the act. As a specific group of contemporary college students, because of their age, environment, level of education and other factors, their legal awareness of the main body of consciousness and the content of consciousness have shown their own characteristics. And they are different from other social groups. College students have not yet formed a mature science life outlook and world outlook, which causes them not comprehensive enough to observe the problem and analyze the problem. Therefore, their legal awareness is with obvious volatility and immaturity. Investigation and research on the legal awareness of this group of college students have a strong practical significance.

\section{The Legal Status of College Students and Analysis}

Chinese contemporary college students' awareness of the law has been awakened and strengthened to a great extent, but most of them only stay on the level of perceptual awareness, and there is a great contrast between "knowledge" and "practice". Among different college students, the level of legal awareness is uneven, which is the same as the behavior of college students. On the one hand, there are an endless stream of cases in which students take legal weapons to defend their legitimate rights and interests. On the other hand, it is not uncommon for college students to break the law or commit crimes such as crimes of theft, marauding or even prostitution, rape and murder, as well as illegal activities such as fights, destruction of public property, plagiarism of academic achievements, arbitrarily tearing up employment contracts, etc.. However, a considerable part of college students is weak in legal awareness and lack the necessary sense of self-protection, which results in the infringement and damage to their own vital interests. In particular, many female undergraduates have not paid enough attention to their own safety and are being cheated in employment and work-study programs. The online dating has fallen into the trap of criminals. The current status of college students' legal awareness mainly shows the following characteristics:

\subsection{Sensitive legal awareness, but the lack of rational legal awareness}

Law itself is a highly disciplined subject. Without a certain basic theory of law, it is difficult to solve the existing legal problems in theory. Most college students are lack of systematic theoretical study of the law, and the legal awareness is still in the emotional state. It should be admitted that contemporary college students have a stronger sense of social responsibility and legal awareness. 
With the accumulation of knowledge and the expansion of their horizons, undergraduates have also begun to learn to think deeply about the reality and pay attention to the legal construction of the state and their own legitimate rights and interests. However, they are often rich in fantasy, anxious for success, lack of a comprehensive understanding of the national conditions, lack of calm, rational analysis, and often showing the tendency of emotional [1]. They focus on achieving self-worth, but often fail to recognize themselves properly and like to treat people and things around with a critical eye. Some people develop their own personality in an extreme manner. Although there is a lot of legal knowledge, in actual life, laws and regulations ranging from school rules and regulations to social laws are regarded as superfluous acts that bind their minds and actions. There is a tendency of opposing psychology and abiding by the law with poor consciousness, and even behaving illegal acts, resulting in the formation of "learning without", "know and not believe" phenomenon. In addition, due to various reasons, the students' confidence in the law is not high, the treatment is basically clear, but the attitude is not strong enough.

\subsection{Influenced by the negative factors of the traditional legal culture in China, college students cannot accurately understand and grasp the basic spirit of the modern legal system}

Due to the long period of feudal society in our country, the law of feudal society unilaterally requires people to abide by the law and requires people to act according to the content stipulated by law only, without giving them equal rights. The formation and precipitation of this "law is a compulsory obligation" awareness affect contemporary college students. Under the legal consciousness of undergraduates, under the negative influence of the "official standard" in traditional culture and judicial corruption existing in reality, there exists the misconception that "law of power is greater than law" and the misconception that people who have power and money can override the law. These negative legal awareness will also seriously affect the establishment of university students' legal belief and the ultimate establishment of the belief in the rule of law. This shows a certain degree of lack of legal belief in college students, but also reflects the law environment and atmosphere that is not conducive to college students. Some college students think the law is the "coercion and restraint" point of view, and they did not form the correct concept of rights and obligations.

\subsection{Legal knowledge is poor with fuzzy legal concepts}

Some college students can not tell the difference between illegal behavior and criminal behavior. They think that illegal is crime and crime is illegal, there is no clear understanding of the difference between the two. Illegal means all violations of the country's constitution, laws, decrees, administrative regulations and administrative rules and regulations, and its extension is extremely extensive. However, crimes must conform to the criminal provisions of the Criminal Law of our country and must possess the following characteristics: First, crime is a crime that endangers the society. The harmfulness of behavior to society is the most essential feature of crime. Second, crime is a crime that violates the criminal law. In other words, acts that endanger the society must simultaneously violate the provisions of the Criminal Law and constitute a crime. Third, the crime must be punishable by penalties, and only those penalties that are punishable by crimes against the society are considered as crimes. The above characteristics are the indispensable conditions for determining any kind of crime. The Criminal Law also stipulates that the circumstances are notable if the plot is not significant and the crime is not serious. This shows that the plot of behavior and the degree of harm to society is the distinction between illegal and criminal boundaries.

The above shows that due to the social negative culture and students' own moral and psychological maturity, the contemporary college students' legal awareness has not yet reached the desired height. Faced with this situation, it is imperative for college students to step up their legal education, and further enhance their legal awareness and legal literacy.

\section{Cultivate and Shape the Main Ways of Modern Legal Awareness of College Students}

Market economy is the rule of law economy. Modern market economy practice requires the 
support of the modern concepts of the rule of law and ethical spirits, which requires corresponding ideological education concepts and operational systems. The quality education of college students includs shaping the modern legal consciousness of college students, which not only relies on schools, but also deeply roots in the "soil" with social background. Therefore, in view of the status quo and analysis of current college students' legal awareness, the following suggestions are put forward:

\subsection{Improve the legal operation mechanism, strengthen the construction of moral standard and create a legal environment and public opinion environment}

However, the world outlook is not yet fully mature and vulnerable to the external environment. Therefore, legislation, law enforcement and the judiciary should be democratized, scientifically and law-enforcing in accordance with laws and regulations. The mass media and various social forces should make use of the exemplary figures and typical deeds those are law popularization, law-abiding, law enforcement and supervision over the law to carry out vivid legal publicity to create a sound legal environment and public opinion environment, which plays an important role in cultivating modern legal awareness of college students [2].

\subsection{Deepen the teaching reform of "Law Basics" in universities and carry out the legal culture activities on campus}

The current "legal basis" textbook generally have the problem that curriculum content set unreasonably. The content of the textbook does not focus on the point, only pay attention to the preparation of the system. The textbook content covers almost the current law in our country, and there is almost no case to explain the corresponding jurisprudence. A large number of legal provisions in the introduction of professional terminology is tantamount to reading bible for non-law students, which does not meet the needs of students' self-study and reading. The "Law Foundation" course should be changed to jurisprudence course or at least should highlight the basic theory of the rule of law, the basic idea of modern law and the basic law of law. At the same time, we should actively expand the categories and scope of law elective courses to meet the interest and needs of students at different levels, so that students have a rational understanding of the basic values and spiritual pursuits of the entire legal system, law and departmental law, so as to gradually train students with higher legal awareness to adapt to the requirements of modern quality education.

Second, classroom education is also very important. Young college students are in the stage of knowledge reserve and ability formation. The main ways to receive education are classroom education in schools, that is, under the careful preparation teachers planned and purposeful teach knowledge according to syllabus. It is the main way for young college students to receive legal knowledge education. The main way for young college students to receive legal knowledge education is law classroom education. Judging from the current university curriculum on the legal aspects of law, in addition to law students, the general non-law students studying law courses are law introduction, legal basis, economic law, tax law, intellectual property law, science and technology law. In recent years, with the social demand for legal talents, employers especially favored the composite legal professionals. The Ministry of Education in 2000 changes in the conditions of law masters admissions (only non-law students enrolled). Combined with China's accession to the WTO, and judicial examination system reform, law courses are popular in colleges and universities students. Students can choose electives, minor, double bachelor, self-study and other channels to learn legal knowledge, and even obtain the relevant qualifications and diplomas. The implementation of the credit system in many colleges and universities has provided broad free space and classrooms for students to learn legal knowledge. The law awareness of undergraduates is undergoing dramatic changes [3].

\subsection{Implementation of "school according to law" creates the atmosphere to cultivate a sense of modern law of college students}

If the rule of law environment in colleges and universities is democratic and equal, it will inevitably have a positive impact on the correct establishment of college students' legal awareness, 
and vice versa. School education and management activities of students have rules, and procedures are legal. When formulating school rules and regulations, schools should ensure that the establishment and use of rules and regulations are not contrary to the spirit of the rule of law and do not conflict with the laws and regulations promulgated and used by the state at the present stage. School should carry out education and teaching in strict accordance with the principles and provisions of education law [4]. Respect the personality of students, safeguard the legitimate rights and interests of students, and form an educating environment in conformity with the spirit of the rule of law so as to continuously raise the legal quality of school administrators and teachers and enhance the ability of schools to handle all kinds of relations according to law.

\subsection{Do a good job legal publicity, and focus on social environmental education}

Human beings are the product of a certain environment. Human consciousness is a reflection of the existence of a certain society and is determined by the existence of society. The formation of individual legal awareness and the external environment are closely related. Young college students are always living in a certain environment, and that the social environment is good or bad has an important influence on the formation of young college students' legal awareness. On the one hand, undergraduates live in a social environment and are affected by all aspects of the real life. To this end, they must give due attention and make corresponding responses. On the other hand, they are members of the real life, and they should make themselves qualified members to adapt to the current social life. We must learn the norms of behavior in the social environment. But also in order to better face society in the future, and in the community struggle to survive, we must seriously consider the immediate social environment. The ideological and behavioral social norms, customs and habits have become the main reference how they adapt to society in the future. Therefore, the education of social environment is one of the important ways to cultivate young college students' modern legal awareness.

Social environment education is mainly through the improvement of the social and legal environment of macro and micro, hardware and software, so that young college students have been educated by the modern legal awareness of the subtle education. From a macro point of view, the social legal environment based on its manifestations and its influence on people with a mandatory can be divided into hardware environment and software environment. Hardware environment mainly refers to the legal system and its facilities, and its influence on people are with mandatory. Software environment mainly refers to legal publicity and education, and the influence of people was without mandatory. The legal education of hardware environment is to optimize the legal environment, establish and improve the legal system, form the external environment of governing the country according to law and educate the young college students with modern legal awareness. Software legal environment education refers to the narrow legal culture and environmental education, that is, make modern legal publicity and education through various carriers and forms, including a variety of legal books, newspapers, publications and other publications, all kinds of legal content, TV, film, drama, folk art, and other art forms. Various slogans, plates, blackboards, windows and other forms of influence on the contents of the rule of law have been greatly influenced. In colleges and universities, special attention should be paid to the influence of the online cultural environment on college students.

\section{Conclusions}

In a word, there are many ways to cultivate the awareness of modern law among young college students. Only by combining the various ways organically and various effective measures be taken can achieve the best results. The cultivation of young college students' awareness of modern law is a complicated systematic project. Due to the continuity, stage and the complexity and diversity of the growth environment of young college students, the whole society is required to mobilize all positive factors in all aspects and to build a college education system suitable for the formation of the modern legal consciousness of young college students. Combines the education of families, schools and all sectors of society to promote the healthy growth of the younger generation. 


\section{Acknowledgements}

The Humanities and Social Sciences Project of Weinan normal University in 2017: status quo and Countermeasures of Integrity Education for College students No.: 17SKYB07

\section{References}

[1] Su Jiansheng, Fan Chuanming. Ideological, moral and legal basis [M]. Beijing: Economic Science Press, 2010.133-135.

[2] Zhang Guangxing. College students moral law training [M]. Shanghai: Science Press, 2009. 234- 235.

[3] Li Qiquan. College students' awareness of legal protection [M]. Anhui: Anhui People's Publishing House, 2010.289-190.

[4] Xiao Jianguo. Community Youth Studies [M]. Shanghai: East China University of Science and Technology Press, 2006.57-60. 